\title{
自由基接力铜催化不对称苄位碳氢键炔基化反应
}

\author{
刘心元* \\ (南方科技大学化学系 广东深圳 518055)
}

\section{Enantioselective Copper-Catalyzed Alkynylation of Benzylic C-H Bonds via Radical Relay}

\author{
Liu, Xinyuan* \\ (Department of Chemistry, Southern University of Science and Technology, Shenzhen, Guangdong 518055)
}

光学纯的炔丙基化合物广泛地存在于天然产物和 活性药物分子中, 同时炔烃官能团在合成化学中有着非 常丰富的转化, 如炔烃可选择性还原转化成相应的烯烃 和烷烃, 还可以氧化成羧酸, 此外炔烃在点击化学中也 有广泛应用等, 因此如何合成光学纯的炔烃类化合物一 直是化学家关注的热点. 在众多方案中, 从碳氢底物出 发, 直接通过碳氢键的不对称炔基化来实现这一转化具 有非常高的效率, 一直是合成化学的热点.

2004 年, 李朝军课题组 ${ }^{[1]}$ 通过发展交叉脱氢偶联策 略, 首次实现了四氢异喹啉氮原子邻位碳氢键不对称炔 基化反应, 反应涉及碳氢键的氧化和原位生成的亚胺正 离子中间体与手性炔基铜亲核试剂的不对称加成反应. 随后多种不对称催化体系先后被报道, 但反应底物均局 限于四氢异喹啉或氮原子上芳基保护的甘氨酸酯类底 物. 最近, 史炳峰课题组 ${ }^{[2]}$ 通过利用手性联䒺二酚配体 和 2-(吡啶-2-基)异丙胺(PIP)辅助基团的共同作用, 实现 了二价钯催化的 $\mathrm{C}\left(\mathrm{sp}^{3}\right)-\mathrm{H}$ 的不对称炔基化反应, 其关 键反应经历金属钯对 $\mathrm{C}\left(\mathrm{sp}^{3}\right)-\mathrm{H}$ 的不对称活化过程. 值 得一提的是, 近期刘心元课题组 ${ }^{[3]}$ 利用一价铜与手性阴 离子配体协同催化的策略, 开发了一系列自由基参与的 不对称反应, 从末端炔烃出发构建了一系列手性炔基化 合物.

刘国生课题组 ${ }^{[4]}$ 长期致力于自由基不对称化学的研 究, 他们发现手性二价铜物种可以选择性地捕捉芐位自 由基, 并以很高的对映体选择性成键; 通过发展铜催化 自由基接力策略, 该课题组成功地实现了芐位及烯丙位 碳氢键的不对称氰化和芳基化等反应; 另外, 他们 ${ }^{[5]}$ 还 发展了烯烃的不对称炔基化反应, 在此基础上, 通过发
展新 Box 配体和氮自由基前体，实现了芐位碳氢键的直 接不对称炔基化反应，高对映体选择性地得到手性炔烃 类化合物; 与林振阳课题组 ${ }^{[6]}$ 合作展开密度泛函(DFT) 计算研究, 结果表明二价炔基铜物种与苄位自由基反应 经历三价铜过渡态的内核(innersphere)反应机制.

作者选用 $\alpha$-乙基萗和三甲氧基 [(三甲基硅基)乙炔 基]硅烷(2a)为反应底物进行条件篮选发现, $\mathrm{CuI}$ 和 $\mathrm{Box}$ 配体 $\mathbf{L 1}$ 为催化剂体系, 修饰的 $N$-氟代双芳基磺酰胺 (NSFI-2) 为氮自由基前体, 无水碳酸钠为碱, 在 1,2,4,5- $\mathrm{F}_{4} \mathrm{C}_{6} \mathrm{H}_{2}$ 和二甲基乙酰胺(DMAc) $(V: V=4: 1$ )的 混合溶剂中, 以 $89 \%$ 的产率和 $93 \%$ ee 值得到目标产物. 值得注意的是, DMAc 作为助溶剂非常关键, 一方面可 以提高反应的收率，但同时也会降低反应的对映选择 性; 相对而言, 在纯四氟苯溶剂中, 反应以 $60 \%$ 的收率 和 $99 \%$ ee 生成手性炔化合物. 另外, 氮自由基前体 (NFSI)的结构对反应的对映体选择性也会产生比较明 显的影响, 作者认为 NFSI 反应产生的氮负离子可能与 二价铜物种中心配位，从而影响自由基反应成键的对映 体选择性.

作者对反应的底物范围进行了考察, 发现标准条件 下 $\alpha$-烷基取代的荎类底物 $(3 \mathbf{a} \sim 3 \mathrm{e})$ 均展现出良好的收率 和优秀的对映选择性 $(90 \% e e)$, 然而对于普通烷基苯类 底物 $(\mathbf{3} \mathbf{f} \sim 3 \mathbf{i})$, 以 Box 为配体, NFSI 为自由基前体时, 反 应表现出更好的收率和高对映选择性(Scheme 1). 其他 种类的炔基硅试剂，也同样适用于该反应，但是要比 $\mathbf{2 a}$ 的活性略低. 需要特别指出的是, 作者探索了底物 4 的 不对称炔基化反应，发现反应具有非常好的区域选择 性，以中等收率(49\%)和优秀的对映体选择性(94\%ee)

* Corresponding author. E-mail: liuxy3@sustech.edu.cn. Published online September 2, 2020. 

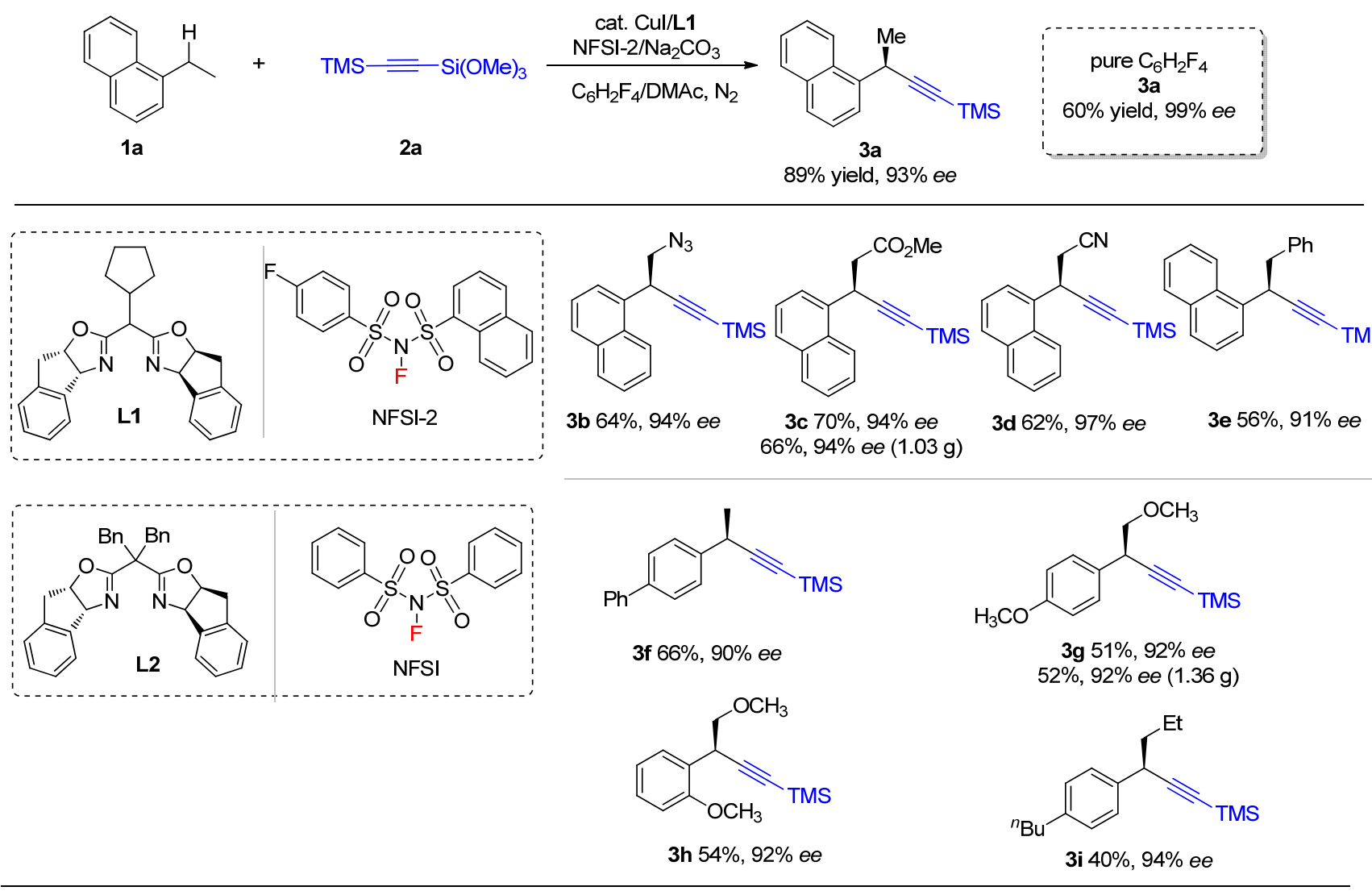

图式 1 不对称苄位碳氢键炔基化

Scheme 1 Asymmetrical benzylic $\mathrm{C}-\mathrm{H}$ alkynylation

得到单一的产物 $\mathbf{5}$, 经过进一步转化, 实现了重要活性 分子 AMG 837 的不对称形式合成(Scheme 2). 随后作者 对手性碳氢键炔基化产物进行转化, 可以得到手性联 烯、烯烃、烷烃以及手性䍨酸等.

作者对反应的机理做了深入的研究. 在标准反应中 添加自由基捕捉剂时反应被抑制，表明反应可能经历了 一个自由基历程, 而且苄位碳氢键断裂是反应的决速步 骤. 另外, 针对苄位自由基与二价炔基铜活性中间体的 机制，与林振阳等合作展开了密度泛函(DFT)计算，研 究结果表明, 与前期报道的 $[\mathrm{Cu}(\mathrm{II})+$ 自由基 $\rightarrow \mathrm{Cu}(\mathrm{III}) \rightarrow$ $\mathrm{Cu}(\mathrm{I})+$ 产物]模式不同，茮位自由基与二价炔基铜物种 的铜中心相结合, 经由三价铜还原消除机制形成碳-碳 键; 计算所得的 $R$ 和 $S$ 构型的能垒差为 $2.6 \mathrm{kcal} / \mathrm{mol}$, 与 实验结果相一致(Scheme 3).

综上, 刘国生与林振阳课题组合作报道了基于铜催 化自由基接力策略的不对称苄位碳氢键炔基化反应, 该 反应底物范围广泛、官能团兼容性好和反应条件温和. 实验和计算结果表明，二价炔基铜活性物种与苄位自由 基的结合经历了三价铜过渡态的过程. 这为后期探索碳 氢键的不对称转化反应提供新的思路.

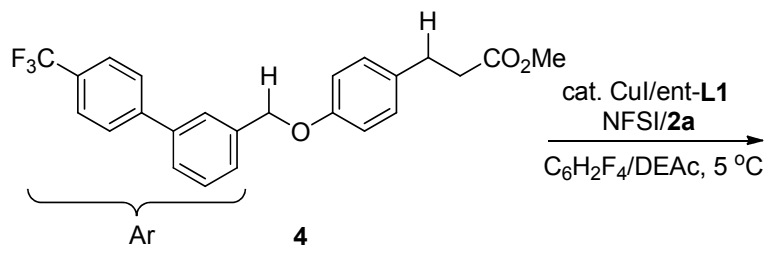

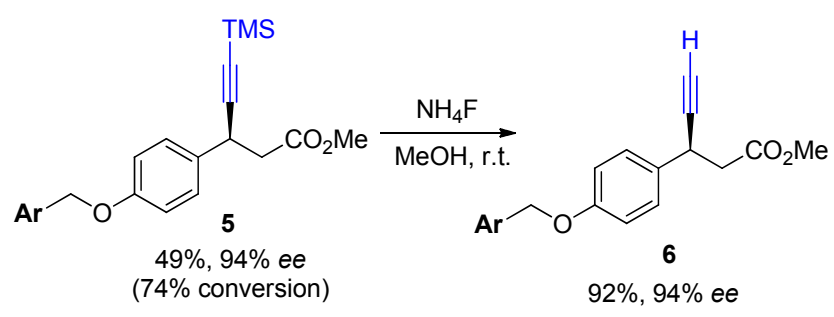<smiles>CC#C[C@H](CC(=O)O)c1ccc(OCc2cccc(-c3ccc(C(F)(F)F)cc3)c2)cc1</smiles>

AMG 837

图式 2 碳氢键的选择性反应及转化

Scheme 2 Site-selective alkynylation and synthetic application 


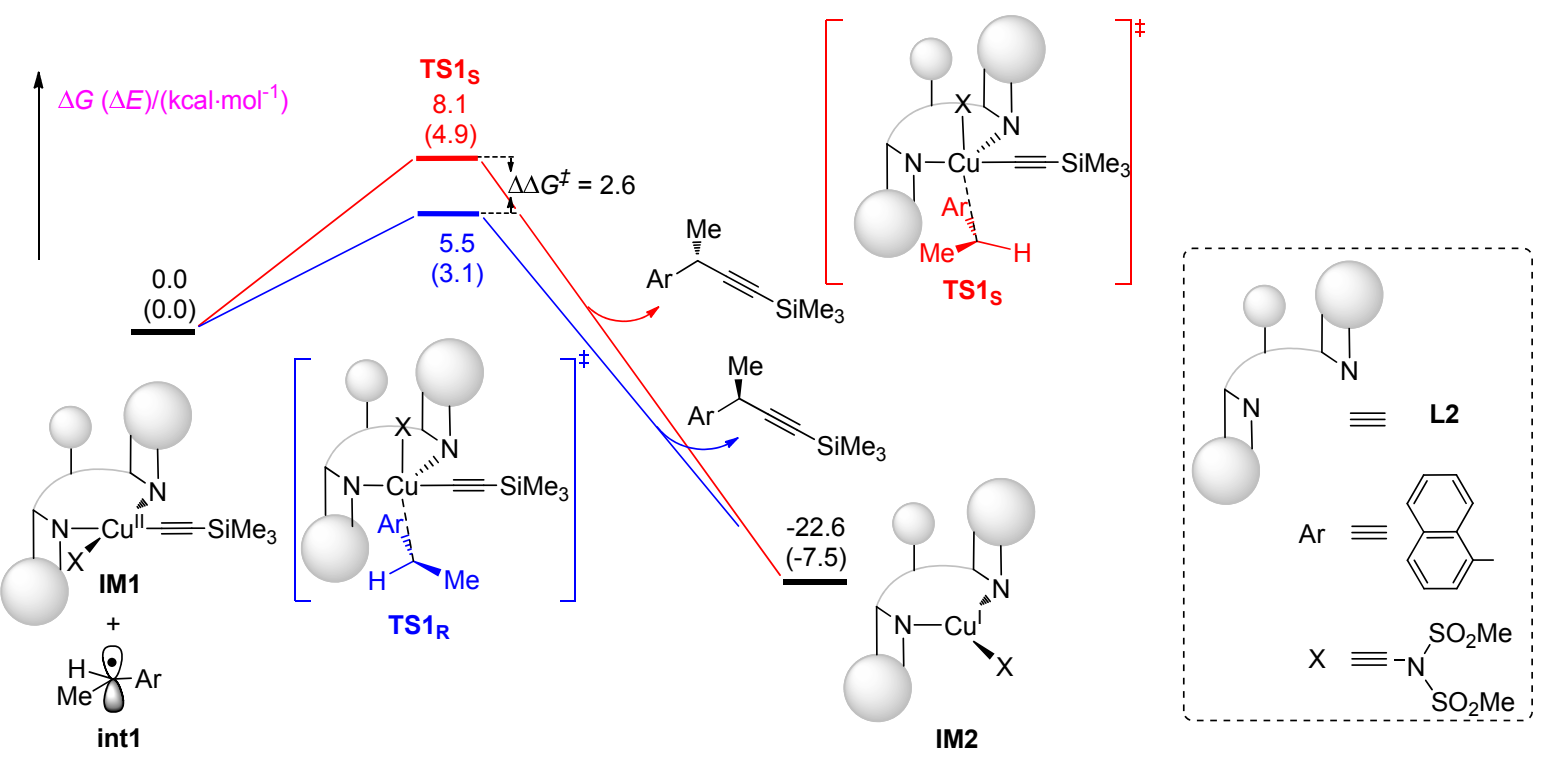

图式 3 DFT 计算

Scheme 3 DFT calculations

\section{References}

[1] (a) Li, C.-J. Acc. Chem. Res. 2009, 42, 335. (b) Li, Z.; Li, C.-J. Org. Lett. 2004, 6, 4997.

[2] Han, Y.-Q.; Ding, Y.; Zhou, T.; Yan, S.-Y.; Song, H.; Shi, B.-F. J. Am. Chem. Soc. 2019, 141, 4558.

[3] (a) Dong, X.-Y.; Zhang, Y.-F.; Ma, C.-L.; Gu, Q.-S.; Li, Z.-L.; Jiang, S.-P.; Liu, X.-Y. Nat. Chem. 2019, 11, 1158.

(b) Zhang, Z.-H.; Dong, X.-Y.; Du, X.-Y.; Gu, Q.-S.; Li, Z.-L.; Liu, X.-Y. Nat. Commun. 2019, 10, 5689.

(c) Dong, X.-Y.; Cheng, J.-T.; Zhang, Y.-F.; Li, Z.-L.; Zhan, T.-Y.; Chen, J.-J.; Wang, F.-L.; Yang, N.-Y.; Ye, L.; Gu, Q.-S.; Liu, X.-Y. J. Am. Chem. Soc. 2020, 142, 9501.

(d) Xia, H.-D.; Li, Z.-L.; Gu, Q.-S.; Dong, X.-Y.; Fang, J.-H.; Du,
X.-Y.; Wang, L.-L.; Liu, X.-Y. Angew. Chem., Int. Ed. 2020, 59, 16926.

[4] (a) Wang, F.; Chen, P.; Liu, G. Acc. Chem. Res. 2018, 51, 2036.

(b) Zhang, W.; Wang, F.; McCann, S. D.; Wang, D.; Chen, P.; Stahl, S. S.; Liu, G. Science 2016, 353, 1014.

(c) Li, J.; Zhang, Z.; Wu, L.; Zhang, W.; Chen, P.; Lin, Z.; Liu, G. Nature 2019, 574, 516 .

(d) Zhang, W.; Wu, L.; Chen, P.; Liu, G. Angew. Chem., Int. Ed. 2019, 58, 6425 .

[5] Fu, L.; Zhou, S.; Wan, X.; Chen, P.; Liu, G. J. Am. Chem. Soc. 2018, 140, 10965.

[6] Fu, L.; Zhang, Z.; Chen, P.; Lin, Z.; Liu, G. J. Am. Chem. Soc. 2020, 142, 12493.

[7] Yazaki, R.; Kumagai, N.; Shibasaki, M. Org. Lett. 2011, 13, 952.

(Zhao, C.) 